\title{
Cultura faz sentido: orientações entre o ontem e o amanhã
}

Culture makes sense: guidelines between yesterday and tomorrow

RÜSEN, Jörn. Cultura faz sentido: orientações entre o ontem e o amanhã. Tradução de Nélio Schneider. Petrópolis: Vozes, 2014. 362p.

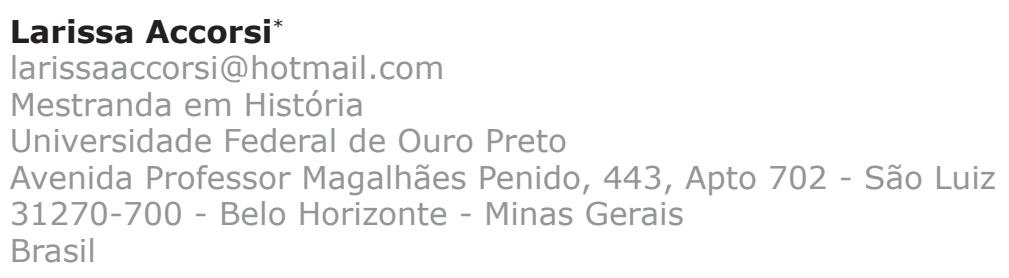

larissaaccorsi@hotmail.com

Mestranda em História

Universidade Federal de Ouro Preto

Avenida Professor Magalhães Penido, 443, Apto 702 - São Luiz

31270-700 - Belo Horizonte - Minas Gerais

Brasil

Palavras-chave

Sentido; Cultura; Didática da história.

Keywords

Sense; Culture; Didatic of history.

\section{8}

Recebido em: 3/9/2015

Aprovado em: 11/1/2016

* Bolsista da Coordenação de Aperfeiçoamento de Pessoal de Nível Superior (CAPES). 
Com uma nova tradução para o idioma português, novamente o público brasileiro tem a oportunidade de entrar em contato com a obra de um contemporâneo teórico da história de notável influência. Cultura faz sentido: orientações entre o ontem e o amanhã reúne uma coletânea de textos em sua maioria já publicados em outra ocasião em alemão, e que podem ser analisados a partir de uma perspectiva de síntese de sua trilogia Teoria da História, uma vez que os cinco aspectos que compõem sua matriz disciplinar perpassam a obra como um todo.

Entretanto, acreditamos que para além desse quadro teórico, o autor concede maior destaque ao conceito que considera ser o ingrediente aglutinador das ciências da cultura em geral, a produção de sentido, de forma a realçar sua importância dentro da matriz disciplinar em consonância com a diversidade cultural do mundo moderno e, por isso, a necessidade de uma cultura do reconhecimento, de uma maior disposição ao diálogo entre as diferentes tradições.

Recentemente homenageado com o título de doutor honoris causa na Universidade de Brasília, Jörn Rüsen, nasceu no ano de 1938 em Diusburgo, na Alemanha, formou-se em história, filosofia, literatura e pedagogia na Universidade de Colônia, onde se doutorou com uma tese sobre Johann Gustav Droysen, em 1966. Sua trajetória acadêmica como professor inclui as universidades de Bochum, Bielefeld (onde sucedeu Reinhart Koselleck no ano de 1989) e Witten-Herdecke, onde permaneceu até se aposentar no ano de 2007. Sua produção científica inclui escritos a respeito da teoria e metodologia da história, historiografia, aprendizagem histórica, e, não menos importante, sobre a consciência histórica e a comunicação intercultural.

Antes de iniciarmos a resenha do livro é necessária uma breve contextualização a respeito de seus contemporâneos para que possamos, em seguida, inseri-lo historicamente em meio intelectual. Rüsen escreve após autores como Reinhart Koselleck, Odo Marquard e Hermann Lübbe, teóricos que possuíam certo ceticismo com relação às grandes narrativas e às prodigiosas expectativas de futuro caídas em descrédito após principalmente a segunda metade do século $X X$.

É importante ressaltar que tais autores, embora sejam conhecidos por integrarem a chamada geração cética, não devem ser associados a tendências pós-modernas da história, ou seja, são denominados céticos devido a sua proximidade e percepção em relação ao momento de intensa instabilidade e desconforto em que se encontrava a Alemanha naquele período. Acreditavam rigorosamente na ciência histórica como um lugar de reflexão e constante mudança do homem em meio social. Além do cenário alemão, Rüsen estava atento também à escola francesa dos Annales, principalmente no que diz respeito a sua proximidade com os métodos das ciências sociais.

Portanto, é possível situarmos a escrita de Rüsen numa época em que o pensamento teórico estava cercado por intensas discussões em torno da pluralização de novas possibilidades de escrita da história e seus métodos, ao mesmo tempo em que o próprio estatuto científico da história e sua capacidade de representação do real estavam em pauta. Dessa forma, Rüsen se insere nesse 
debate mostrando que mesmo em meio a multiplicação de novos objetos e de novas formas de apreensão do real, era necessário aos historiadores que, desde o princípio de suas análises, tivessem em conta uma visão geral da disciplina histórica, a qual o autor conceituou como matriz disciplinar.

Cultura faz sentido: orientações entre o ontem e o amanhã é um livro dividido em quatro partes, cada uma contando com três ou quatro textos. A primeira parte denominada "Apropriações da tradição", mostra que o eixo das argumentações gira em torno das discussões da pós-modernidade, onde, Rüsen de forma eloquente retoma alguns dos escritos clássicos do pensamento teóricofilosófico de Kant, Lessing e Droysen à luz de novas interpretações.

Intitulada "Impulsos do pensamento teórico", a segunda parte reúne um conjunto de textos que mostram num exemplo concreto a adequação de boa parte de seu quadro teórico relativo à produção de sentido. Rüsen se utiliza da memoraçãoda sociedade alemã, mostrando como as gerações posteriores a derrota na segunda guerra e, sobretudo, após o holocausto, tiveram posturas distintas à maneira pela qual lidaram com o passado e, como conseguiram incluir tais eventos em sua cultura, revelando como o sentido atua em meio à sociedade.

A terceira e a quarta partes, respectivamente "Cultura da ciência" e "Potencialidades na formação de sentido", trazem discussões mais pontuais sobre o que vem a ser o sentido e qual seu lugar no pensamento científico e, sobretudo, no mundo da vida.

Ainda na introdução do livro, Rüsen afirma o que para alguns poderia 190 indicar um nonsense teórico ao salientar a necessidade de reabilitação de uma filosofia da história. No entanto, vale sublinhar que desde o Iluminismo tal conceito se multiplicou em diversas outras vertentes, como bem argumenta Odo Marquard. Portanto, para Rüsen o que interessa é recuperar seu aspecto de totalidade em função da própria heterogeneidade que the é inerente, pois o conceito de etnocentrismo nos diz que um grupo se delimita em função da diferença do outro, ou seja, o cerne da questão para Rüsen é que ao nos posicionarmos frente à alteridade o fazemos a partir de extremos excludentes.

A proposta de Rüsen de uma reabilitação da filosofia da história pode ser equiparada ao seu conceito de matriz disciplinar, visto que este pode ser lido como uma espécie de quadro teórico, onde, a partir de um ponto de vista geral, é possível produzir interpretações ou, a rigor, não excluir diversas outras perspectivas. Sua única condição, ou melhor, o ponto de partida de qualquer teoria diz respeito à estreita relação que necessariamente deve coexistir entre pensamento científico e vida cotidiana; esse é início de qualquer análise histórica.

Desta maneira, para uma análise cultural que seja capaz de tematizar os inúmeros fenômenos de um grupo de pessoas, Rüsen afirma que ela só pode ser feita a partir de uma narrativa mestra, pois, caso contrário, cairíamos naquela mesma filosofia hoje intensamente criticada. A questão narrativa ocupa em Rüsen um lugar comum por meio do qual o conhecimento científico é apresentado e levado ao mundo da vida, de modo que as críticas dirigidas às narrativas como textos literários e por isso ficcionais não encontram lugar em 
seu pensamento, pois, tanto a linguagem como a pesquisa científica cumprem papéis essenciais e interdependentes em seu quadro teórico.

Um dos textos mais expressivos do livro é "Segundo Kant: ideia europeia da história universal com propósito intercultural", onde Rüsen faz uma releitura do clássico texto de Kant, "Ideia de uma História Universal de um Ponto de Vista Cosmopolita", publicado pela primeira vez no ano de 1784, de forma a mostrar que em meio à era globalizada, onde os processos de sociabilidade se tornam cada vez mais inflexíveis, o papel das ciências culturais é problematizar as diferenças em favor de uma melhor convivência entres as diversas culturas.

Rüsen sublinha a necessidade de todas as culturas de estabelecer uma narrativa mestra que seja capaz de expor suas especificidades e diferenças em relação ao outro, pois a questão da não aceitação de uma narrativa universal diz respeito àquela filosofia da história da época das luzes, onde a cultura do Ocidente foi tomada como a principal e assim, produziu a depreciação de sociedades não ocidentais, além de genocídios e crimes contra a humanidade.

Portanto, a releitura de Kant além de retomar discussões em torno da estrutura das narrativas totalizantes, chama a atenção, à medida que mostra ser possível e necessária uma historiografia comparada intercultural, sendo esta também uma das principais funções da história em meio à rapidez e à fluidez das comunicações entre os indivíduos, "quando se trata, portanto, de englobar fundamentalmente as diferenças culturais em perspectiva histórica e de modo universalista, a perspectiva kantiana de história universal continua convincente" (RÜSEN 2014, p. 23).

Memoração, enquanto ato de trazer à tona memórias, seria, para Rüsen, um conceito chave para compreendermos uma das formas pelas quais o sentido se manifesta, pois é partir dela - da memoração - que podem surgir orientações para o agir cotidiano, uma vez que ela tem por finalidade orientar o presente e preparar também o futuro. Memorações são comumente ativadas quando a coerência habitual das coisas é quebrada e precisamos reaver algum momento passado para provermos de sentido, de alguma forma, o presente. Entretanto, há também um âmbito menos positivo desse tipo de operação tão valorizado a partir da virada culturalista, pois lado a lado com a consciência histórica, a memoração, de acordo com Rüsen, necessita ainda de uma melhor reflexão teórica que explique de forma mais clara sua atividade.

Quando nos perguntamos pela função da memoração no processo de formação de identidade, a resposta de Rüsen nos encaminha para o exemplo da sociedade alemã pós 45 , onde o passado, através de uma dimensão estética, simbólica e afetivase faz presente através de espaços físicos, que os "permitem experimentar de maneira imediata a diferença entre passado e presente, e nessa experiência da diferença, dão início à memoração coletiva e possibilitam um discurso público" (RÜSEN 2014, p. 116). Portanto, a construção de lugares de memória, enquanto lugar produtor de sentido, além de manter acessível à lembrança do passado, serve para sinalizar, sobretudo, de modo instrutivo uma mudança histórica.

É evidente que Rüsen tem em mente as dificuldades de se estabelecer uma cultura europeia, tanto em âmbito nacional como regional, entretanto, ele 
sublinha que os aspectos diferentes, e até mesmo depreciativos, que compõem tais sociedades devem ser vistos como uma "força propulsora da própria união europeia" (RÜSEN 2014, p. 142). Um exemplo que pode elucidar melhor a questão foi a reunificação das duas Alemanhas, onde, nas palavras de Rüsen, não bastou "um distanciamento crítico, nem um inventário de devastações" (RÜSEN 2014, p. 142). Há que se pensar para além da rasa dicotomia entre vítima e algoz de uma vez por todas e, através dos diversos meios produção de sentido buscar novas direções nas produções científicas que, na visão do autor, certamente terão algum impacto sobre a vida prática.

Outra atribuição do sentido frente a essas breves considerações aqui realizadas, pode surgir, como preconiza Rüsen, a partir de quatro operações mentais expostas por tipos ideais: 1) a experiência histórica: onde o tempo é experimentado para que possamos prosseguir mesmo em meio a contingências; 2) a interpretação: forma pela qual se torna possível lidar com a contingência e, o presente passa a ser visto como espaço permissível de mudança; 3) orientação: onde as interpretações podem ser de fato executadas; 4) motivação: quando o tempo interpretado é "enviado ao endereço da vontade humana" (RÜSEN 2014, p. 185). De forma simples e direta, o passar do tempo se torna algo que faz sentido no e principalmente para o presente.

Outro ponto que acreditamos ser uma boa contribuição do livro diz respeito à didática da história, onde o autor demonstra, a partir da exposição dos múltiplos aspectos que envolvem a construção do pensamento histórico, a finalidade e/

192 ou a função da história em seu leque mais amplo, seja: o de mostrar como o aprendizado histórico está associado diretamente à competência experiencial, ou seja, o sentido funciona como a porta de entrada para que o passado adquira algum significado para o presente. Assevera que o ensino e a aprendizagem da história, para se tornarem efetivamente ativos, devem ser explorados a partir de algo que tenha alguma significação para o mundo da vida.

Sobre o que tanto gostam de discutir os pós-modernos sobre a história ter - ou não - uma função efetiva para o agir humano, Rüsen, assim como Koselleck, buscou em Husserl o que ele chamou de "retenções" e "protensões", ou seja, não há sequer um ato humano que não seja baseado num período anterior ao exato presente e, que não esteja em conexão com uma futura ação. Ressalvo que não estamos falando aqui de um futuro longínquo, mas de um tempo dinâmico do próprio cotidiano. À vista disso, completando o ciclo de sua matriz disciplinar o autor conclui que a produção de sentido está presente em todas as esferas da vida, logo, as ciências são também parte daquilo que elas mesmas investigam - isto deve ser algo claro para aqueles se dedicam a investigar o mundo de forma científica, salienta Rüsen.

Dessa maneira, quando pensamos que as consequências da Modernidade trazem consigo o que Max Weber chamou de "desencantamento do mundo" ou como sugeriu Odo Marquard, que uma das funções da história seria a de compensar os danos causados pelo excesso de racionalização, Rüsen responde que é exatamente em função de todas essas mazelas que ela deve atuar como força orientadora capaz de buscar no passado elementos que ainda hoje fazem 
sentido e trazê-los para a reflexão para que, de alguma forma, consigam preparar o terreno para o porvir. "Os envolvidos devem, como foi dito, interpretar o evento temporal do seu próprio mundo e de si mesmos para poderem efetuar em vida a sua própria temporalidade e apropriar-se dela. Eles precisam dar-Ihe um sentido com o qual se relacionam com ele" (RÜSEN 2014, p. 256).

É permissível afirmar então que a produção de sentido, enquanto um lugar a partir do qual nossas carências de orientação são percebidas e, então ativadas, é o momento onde direcionamos nossas perspectivas orientadoras no dia a dia que, a rigor, servem de base para os interesses científicos que, devidamente elaborados através de regras que fundamentam as pesquisas empíricas, retornam para a vida prática. Dito isso, notamos que o componente do sentido desde há muito está presente em sua obra, no entanto, é neste livro em específico que ele aparece como um elemento essencial de sua matriz disciplinar.

\section{Referências bibliográficas}

ASSIS, Arthur. A teoria da história de Jörn Rüsen: uma introdução. Goiás: Editora UFG, 2010.

RÜSEN, Jörn. Cultura faz sentido: orientações entre o ontem e o amanhã. Tradução de Nélio Schneider. Petrópolis: Vozes, 2014.

História Viva: teoria da história: formas e funções do conhecimento histórico. Brasília: Editora UnB, 2007.

. Razão histórica: teoria da história: fundamentos da ciência histórica. Brasília: Editora UNB, 2010.

Reconstrução do passado. Brasília: Editora UnB, 2007. 